\title{
Evaluation of Two Rapid Field Level Diagnostic Tools for Acute Canine Leptospirosis in an Endemic Area
}

\author{
R. Ambily ${ }^{1}$, M. Mini ${ }^{1}$, Siju Joseph ${ }^{1}$ and S.V. Krishna ${ }^{2}$ \\ ${ }^{1}$ Department of Veterinary Microbiology, College of Veterinary and Animal Sciences, \\ Mannuthy -680 651, India \\ ${ }^{2}$ Department of Veterinary Microbiology, College of Veterinary Science, \\ Mamnoor Warangal Dist., India \\ *Corresponding author
}

A B S T R A C T

The present study aims at evaluating the efficacy of two rapid tools, IgM dot ELISA and Latex Agglutination Test employing recombinant LipL32 as antigen in diagnosing acute leptospirosis in dogs in Kerala, a disease endemic area. One hundred and five serum samples were collected from dogs presented at Veterinary Hospitals attached to Kerala

\begin{tabular}{|l|}
\hline Ke y w or d s \\
Acute canine \\
leptospirosis, \\
pPro.EX.HtC, IgM \\
dot ELISA, IgM \\
plate ELISA
\end{tabular}
Veterinary and Animal Sciences University during the period from September 2014 to May 2016. Microscopic Agglutination test was carried out using the reference strains maintained in the Dept. of Veterinary Microbiology, College of Veterinary and Animal Sciences, Mannuthy. In MAT, samples with titre $\geq 1: 800$ were considered as positive. For recombinant LipL32 protein production, the lipl32 gene of Leptospira interrogans was ligated with prokaryotic expression vector pPro.EX.HtC and transformed into competent E. coli DH5 $\alpha$ cells. The clones were induced with Isopropyl $\beta$-D-1-thiogalactopyranoside (IPTG) and the protein was purified using Nickel affinity chromatography and used as antigen in IgM dot ELISA, plate ELISA and Latex Agglutination Test (LAT). All the 105 samples were subjected to the three tests. The relative sensitivity and specificity of IgM dot ELISA, plate ELISA and LAT were evaluated in comparison with MAT. Among the 105 samples, 56 were found to have a titre of $\geq 1: 800$ in MAT. In IgM dot ELISA, 55 samples were found to be positive and one was negative. Latex Agglutination Test detected 58 samples as positive. It was found to be a less specific (91.84 \%) test than IgM dot ELISA in detecting acute leptospirosis although it was found to be sensitive (96.43\%). IgM dot ELISA was proved to be sensitive $(96.43 \%)$ and specific $(97.96 \%)$ and the results were more satisfactory than IgM plate ELISA in detecting acute cases of leptospirosis which is very relevant in an endemic area like Kerala.

\section{Introduction}

Leptospirosis is highly endemic in Kerala affecting human beings and animals. The disease is often under-diagnosed because of non-specific symptoms, inadequate surveillance system and lack of readily available quick and simple diagnostic tests (Picardeau, 2013). The infection is totally amenable to treatment, if it is diagnosed at its 
early acute phase (Toyokawa et al., 2011). A wide range of domestic and wild animals are known to be affected with the disease and the dogs serve as immediate source of infection to humans. Therefore, early diagnosis of canine leptospirosis is of prime importance to prevent its transmission to humans especially in areas of high endemicity.

Routine diagnostic methods include dark field microcopy, isolation of the bacteria and Microscopic Agglutination Test (MAT) which are either time consuming or cumbersome. Polymerase Chain Reaction (PCR) provides significantly faster results during the very early stages of the infection, but cannot be employed as a rapid diagnostic tool (Levett, 2003). So the diagnosis of leptospirosis is focused on the detection of leptospiral antibodies which appear within three to seven days after infection. The accurate result of serological test depends on the efficiency of the antigen also. The protein profile of outer membranes revealed the major band at approximately $32 \mathrm{kDa}$ molecular weight (Haake et al., 2000; Abhinay et al., 2012), which is immunogenic (Hauk et al., 2011). The recombinant LipL32 (rLipL 32) protein is an optimal antigen for serodiagnosis of leptospirosis (Zhang et al., 2005) and ELISA based on this protein is a good diagnostic tool for leptospirosis (Dey et al., 2004), which is easier to perform, can accommodate a large number of samples and gives a less subjective result than MAT. However, plate ELISA is unfit for the routine field level diagnosis. Therefore, a simplified version of ELISA such as dot ELISA is commonly used (Sharma et al., 2007). Latex Agglutination Test (LAT) has been widely employed as a screening test for leptospirosis (Senthilkumar, 2007). The present study aims at evaluating rLipL32 based dot ELISA and LAT as rapid diagnostic tools in comparison with the standard test MAT in detecting leptospiral antibodies in acute cases of leptospirosis in dogs in an endemic area.

\section{Materials and Methods}

\section{Sample collection}

One hundred and five serum samples were collected from dogs presented at Veterinary Hospitals attached to Kerala Veterinary and Animal Sciences University and from nearby hospitals during the period from September 2014 to May 2016.

\section{Microscopic agglutination test}

The reference serovars used as antigens in MAT were Leptospira interrogans serovars Australis, Autumnalis, Canicola, Grippotyphosa, Icterohaemorrhagiae, Javanica, Pomona, Pyrogenes and Bataviae. The test was carried out as described by Faine et al., (1999). In the first step, 1:800 serum dilutions was prepared in PBS, $30 \mu \mathrm{L}$ of which is taken and mixed with $30 \mu \mathrm{L}$ of each of the six day old live leptospiral serovars separately. Antigen controls were set with 30 $\mu \mathrm{L}$ PBS and $30 \mu \mathrm{L}$ of different live leptospiral serovars and the plates were incubated at $37^{\circ} \mathrm{C}$ for two hours. After incubation, the result was read by examining a drop of serum-antigen mixture from each well under low power of DFM for agglutination of leptospires. The combination at which 50 per cent or more leptospiral organisms were seen agglutinated was taken as positive. In MAT, samples with titre $\geq 1: 800$ were considered as positive (Ooteman et al., 2006).

\section{Recombinant LipL32 protein production}

For recombinant LipL32 protein production, the lipl32 gene of Leptospira interrogans was digested with restriction enzymes, Sal1 and Pst 1 (MBI, Fermentas) and ligated with prokaryotic expression vector pPro. EX.HtC and transformed into competent $E$. coli $\mathrm{DH} 5 \alpha$ cells. The transformation was confirmed by colony PCR (Fig. 1). The clones were induced with Isopropyl $\beta$-D-1-thiogalactopyranoside 
(IPTG) and were analyzed using SDS-PAGE (Fig. 2). The protein was purified using Nickel affinity chromatography, immunoblotted to confirm the immunogenicity and used as antigen in IgM dot ELISA, plate ELISA and LAT.

\section{IgM ELISA}

All the 105 samples were also subjected to plate ELISA (Ooteman et al., 2006). The optimum concentration of the antigen for ELISA was found out employing the checker board analysis. The recombinant LipL32 antigen was diluted in carbonate bicarbonate buffer so as to incorporate the antigen concentration ranging from $25 \mathrm{ng}, 50 \mathrm{ng}, 100$ ng, $150 \mathrm{ng}, 200 \mathrm{ng}$ and $250 \mathrm{ng}$ per well. Similarly, serum samples were taken in the dilutions ranging from 1: 50 to 1: 400. In IgM ELISA, rabbit anti canine IgM peroxidase conjugate was used. The cut-off value for the interpretation of ELISA was determined as per the report of Bomfim et al., (2005). The mean OD with 40 negative sera was recorded by performing ELISA. The negative sera used were those collected from healthy unvaccinated animals with MAT titre less than
1:50. Then, the cut off value was determined using the formula Mean OD $+3 \times$ Standard deviation. The optimum concentration of antigen was found to be $50 \mathrm{ng} /$ well and 150 $\mathrm{ng} /$ well for rLipL32. The rabbit anti-canine IgG HRP conjugate concentration estimated was 1:2000. A 1:50 dilution of test serum was found optimum working dilution. The relative sensitivity, specificity and accuracy of $\operatorname{IgM}$ dot ELISA, plate ELISA and LAT were evaluated in comparison with MAT.

\section{Results and Discussion}

The results of MAT, IgM dot ELISA, LAT and IgM plate ELISA are given in table 1. Among the 105 samples, 56 were found to have a titre of $\geq 1: 800$ in MAT (Fig. 3). In IgM dot ELISA, 55 samples were found to be positive and one was negative. Latex Agglutination Test could detect 58 samples as positive. Comparison of the results with MAT is presented in table 2. The diagnosis of acute leptospirosis in dogs is a dilemma in endemic areas like Kerala, where routine vaccination is practiced, because the vaccinal antibodies and past infections always interfere with the results.

Table.1 Results of MAT, IgM dot ELISA and IgM plate ELISA

\begin{tabular}{|l|l|l|l|l|l|l|l|}
\hline \multirow{2}{*}{ MAT } & \multicolumn{3}{l|l}{ IgM dot ELISA } & \multicolumn{2}{l|}{ LAT } & \multicolumn{2}{l|}{ IgM plate ELISA } \\
\cline { 3 - 8 } & $+\mathrm{VE}$ & $-\mathrm{VE}$ & $+\mathrm{VE}$ & $-\mathrm{VE}$ & $+\mathrm{VE}$ & $-\mathrm{VE}$ \\
\hline+ +VE & 56 & 54 & 2 & 54 & 2 & 52 & 4 \\
\hline -VE & 49 & 1 & 48 & 4 & 45 & 2 & 47 \\
\hline
\end{tabular}

Table.2 Comparison of ELISAs and LAT in comparison with MAT

\begin{tabular}{|l|l|l|l|}
\hline & IgM dot ELISA & LAT & IgM plate ELISA \\
\hline Sensitivity & $96.43 \%$ & $96.43 \%$ & $92.86 \%$ \\
\hline Specificity & $97.96 \%$ & $91.84 \%$ & $95.92 \%$ \\
\hline Positive Likelihood Ratio & 47.05 & 11.81 & 22.75 \\
\hline Negative Likelihood Ratio & 0.04 & 0.04 & 0.07 \\
\hline
\end{tabular}


Fig.1 Confirmation of clones by colony PCR

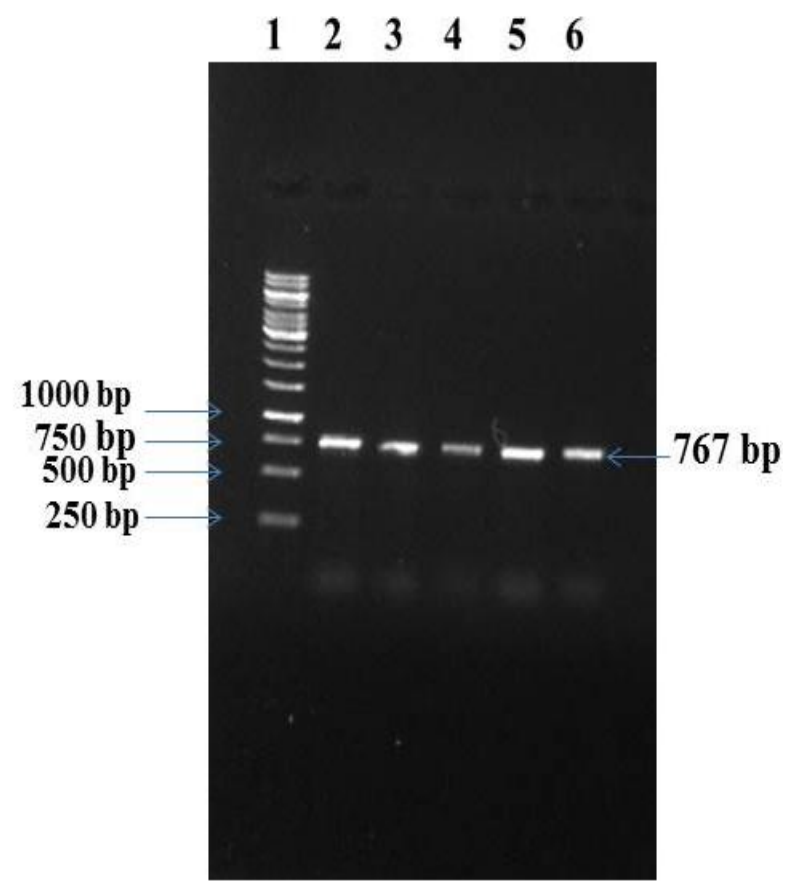

(b)

Lane 1-1 kb marker

Lane2 to 6-amplified lipl32 genes

from transformed colonies

Fig.2 Induction of recombinant LipL 32 protein

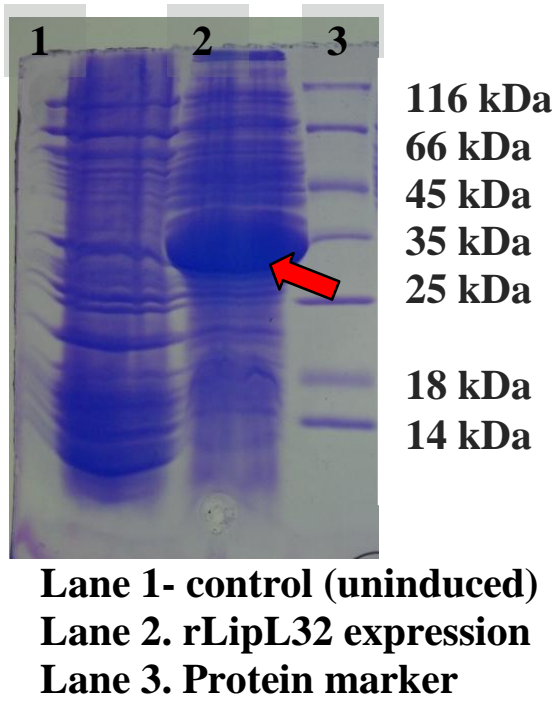


Fig.3 Microscopic agglutination test (Representation)

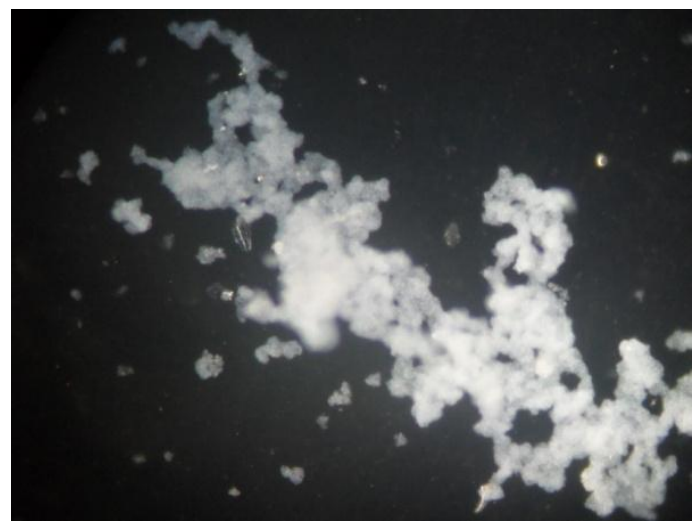

1 in 400 dilution of test serum

As leptospirosis in dogs as well as human beings is completely amenable to treatment, prompt detection is quintessential for effective therapy and management of the disease. The conventional diagnostic tests cannot be resorted to as they are time consuming and proved to be limited to well equipped laboratories. Hence, impetus is being given to rapid field level diagnostic methods. In this study, recombinant LipL32 based IgM dot ELISA and LAT were evaluated as diagnostic tools for canine leptospirosis. In MAT, a titre of $\geq 1: 800$ was taken as positive (Ooteman et al., 2006). Among the 105 samples, 56 (53.33 percent) were found to have a titre of $\geq 1: 800$ in MAT, indicating acute leptospirosis. IgM dot ELISA revealed 55 samples as positive and one was negative. Latex Agglutination Test could detect 58 samples as positive. This test detected four MAT negative samples as positive, three of which had a MAT titre of 1: 200. This is insignificant in an endemic area. This low antibody titre may be of vaccinations or past infection which cannot be differentiated in LAT. In one LAT positive sample, the MAT titre was < 1:50. Two MAT positive samples were detected as negative in LAT. IgM dot ELISA was found to be sensitive and specific in detecting acute cases of leptospirosis which is very relevant in an endemic area like Kerala. The tests could not

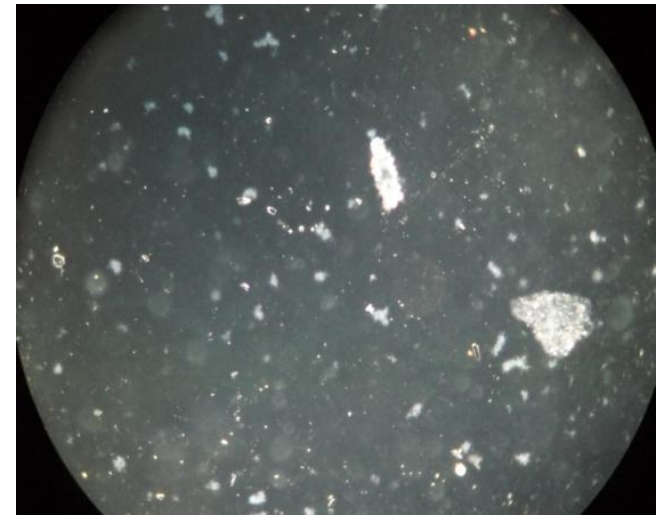

1 in 800 dilution of test serum

achieve 100 per cent sensitivity since some of the MAT positive samples were found to be negative to IgM antibodies. The antibodies detected in MAT could be IgG antibodies which were not detected in dot ELISA. The presence of $\operatorname{IgM}$ antibodies is the indication of immediate infection whereas IgG antibodies may be due to past infections. The LAT proved to be a less specific test than IgM dot ELISA in detecting acute leptospirosis although it was found to be sensitive ( 96.43 per cent). Moreover, LAT could not differentiate past infections and vaccinates.

From the present study, it can be concluded that rLipL32 based IgM dot ELISA was found to be the specific test in rapid field level diagnosis of acute canine leptospirosis in an endemic area like Kerala.

\section{References}

Abhinay G, Ambily R and Joseph S. (2012). IgM immunoprofile of leptospiral outer membrane proteins in acute canine leptospirosis. Indian Vet. J. 89(1): 0910.

Dey S, Mohan M, Senthilkumar T M A, Ramadass P, Nainar M A and Nachimuthu K. (2004). Recombinant LipL32 antigen-based single serum dilution ELISA for detection of canine 
leptospirosis. Vet. Microbiol.103: 99106.

Faine S, Adler B, Bolin C A and Perolat P (1999). Leptospira and leptospirosis, $\left(2^{\text {nd }}\right.$ Ed.) Medi Sci, Melbourne, Australia. 272 pp.

Haake D A, Chao G, Zuerner R L, Barnett J K, Barnett D, Mazel M, Matsunaga L, Levett P N and Bolin C A. (2000). The leptospiral major outer membrane protein LipL32 is a lipoprotein expressed during mammalian infection. Infect. Immun. 68: 2276-2285.

Hauk, P., Carvalho, E. and Ho, P.L. 2011.Expression and purification of the non-tagged LipL32 of pathogenic Leptospira. Braz. J. Med. Biol. Res.44: 297-302.

Levett P.N. 2003. Leptospira and leptonema. In: Murray, P.R., Baron, E.J., Jorgensen, J.H., Pfaller, M.A. and Yolken, R.H. (eds.), Manual of clinical microbiology, American Society for Microbiology, Washington, D.C. 936 pp Ooteman M C, Vago A R and Koury M C (2006). Evaluation of MAT, IgM ELISA and PCR methods for diagnosis of human leptospirosis. J. Microbiol.
Meth. 65: 247-257

Picardeau M. (2013). Diagnosis and epidemiology of leptospirosis. Med. Mal. Infect. 43(1):1-9.

Sariprabha P. (2010). Evaluation of whole cell antigen and outer membrane protein based latex agglutination test for serodiagnosis of canine leptospirosis. M. V. Sc. Thesis, Kerala Agricultural University, Thrissur, 75p.

Sharma R, Tuteja U, Shukla R K J and Batra H V (2007). Application of rapid dotELISA for antibody detection of leptospirosis. J. Med. Microbiol. 56: 873-874

Toyokawa T, Ohnishi $\mathrm{M}$ and Koizumi N. (2011). Diagnosis of acute leptospirosis. Expert Rev. Anti Infect. Ther. 9(1):11121.

Zhang XY, Yu Y, He P, Zhang YX, Hu BY, Yang Y, Nie YX, Jiang XG, Zhao GP, Guo XK. (2005). Expression and comparative analysis of genes encoding outer membrane proteins LipL21, LipL32 and OmpL1 in epidemic leptospires. Acta Biochem. Biophys. Sin. (Shanghai). 37(10):649-656.

\section{How to cite this article:}

Ambily, R., M. Mini, Siju Joseph and Krishna, S.V. 2019. Evaluation of Two Rapid Field Level Diagnostic Tools for Acute Canine Leptospirosis in an Endemic Area. Int.J.Curr.Microbiol.App.Sci. 8(02): 10-15. doi: https://doi.org/10.20546/ijcmas.2019.802.003 